\title{
An Analysis of Consumers' Preferences between Locally Grown/Processed Food and Organic Food
}

\author{
John Stanton ${ }^{1 *}$, Ferdinand F Wirth ${ }^{2}$ and Yingdao Dao ${ }^{3}$ \\ ${ }^{1}$ Department of Food Marketing, Saint Joseph's University, USA \\ ${ }^{2}$ Associate Professor of food Marketing, Saint Joseph's University, USA \\ ${ }^{3}$ Research assistant, Saint Joseph's University
}

Received: 海 August 06, 2018; Published: 海 August 17, 2018

*Corresponding author: John Stanton, Department of Food Marketing, Saint Joseph's University, USA

\begin{abstract}
Consumer selectivity when buying food, due to concerns for food safety, personal health, and environment sustainability, has led to the growing popularity for "organic" and "local" product labels. Little research has examined consumer preferences and tradeoffs between organic and local when both choices are available. This paper investigates the structure of consumers' preferences for three separate food groups and measures the relative importance of local versus organic in the context of other desired category-specific product attributes. For all three product groups, local was more important that organic, but other category-specific attributes were more important in a purchase decision.
\end{abstract}

Keywords: Conjoint analysis; Organic; Locally grown

\section{Introduction}

With apparent concerns for food safety, personal health, and environment sustainability, research has shown that consumers are selective when they purchase and consume food [1]. This selectivity has led to the growing popularity for "organic" and "local" (including "locally grown" and "locally produced") labels among consumers. The U.S. Department of Agriculture (USDA) counted 19,474 organic farms, ranches and processing facilities in 2015, up more than $5 \%$ from the previous year and $250 \%$ from 2002 [2]. Indeed, organic food sales have increased $13.1 \%$ from July 2015 to July 2016 [3]. The rise in 'local' or 'locally grown' is mirrored in the growth of the numbers of farmers' markets in the United States. Since 2002, the number of farmers' markets has increased fourfold to over 8,400 farmers' markets, almost four times more than in 1994 [4].

Organic food is well defined by the USDA, which in effect requires no chemicals be used in the farming process. The USDA guidelines include [5]:

a) Produced without excluded methods, (e.g., genetic engineering, ionizing radiation, or sewage sludge).

b) Produced using allowed substances such as non-synthetic pesticides and herbicides.

c) Overseen by a USDA National Organic Program-authorized certifying agent, following all USDA organic regulations.
While many consumers associate animal welfare and/or environmentally friendly attributes, according to the USDA these are not necessary to be labelled organic. Local food has no official government definition. In fact, previous research has shown that there is a substantial variation in consumers' concept of local food [6]. In this research, the authors have let each consumer consider his or her own definition of local.

Growth in the organic and local markets is not without complications. The yield of organic food is less than that of conventional food, and the shortage of affordable organic ingredients or products, such as corn and soybeans for livestock feed, left organic producers unable to meet market demand [7]. To meet the continuously growing demand for organic food, overseas imports of organic food are being sold in the US market. However, because the standards of food growth and processing procedures vary from country to country, consumers have credence problems with organic food from overseas [8,9]. While purchasing local alleviates concern of outsourced organic food, the local label is far less regulated than the organic label in U.S. While there has been a significant amount of research on both organic and local as shown in the literature review section, no research has examined consumer preferences when both choices are available. That is, when consumers have a choice of organic but not local and local but not organic, what tradeoffs will be made. More simply stated, do 
consumers prefer local food over organic or vice versa? This paper investigates consumers' preferences between locally grown food and organic food when both choices are available. The importance of these attributes will be measured in the context of other desired product attributes. Additionally, the analysis will be done on three separate food groups to verify that the findings may not be category specific.

This research will expand the literature by addressing the following questions:

a) Which production method (local/organic) will consumers choose when both organic food and locally grown food are available in a market at the same time?

b) What is the relative impact of utility for organic and locally grown labels when both organic food and locally grown food are independently available and not in combination?

c) Will the food category influence consumers' decisions between organic and locally grown foods when both options are available independently?

\section{A Review of the Growing Organic and Local Markets}

The following provides a review of these two growing markets and discusses prior research into consumer independent preferences for these production methods.

\section{Rise and preference for organic foods}

Since the introduction of the USDA National Organic Program in 2002, the demand for more organic products has steadily risen in the United States. According to Operations Research Perspective, companies can expect solid growth for the US organic food market to continue until 2018, according to a new report that puts a compound annual growth rate (CAGR) of $14 \%$ on the sector [10] There is a significant body of literature suggesting that personal health concerns are another key motivation for consumers to purchase organic food [11-16]. However other research has shown the primary reasons consumers purchase organic food are: environmental, and animal welfare concerns [17]. According to Zepeda [1], the more organic foods a consumer consumes, the more likely (s)he is to espouse environmental motivations over health concerns. Organic food is perceived as being less harmful to the environment, contributing less to air, water, and soil pollution. Related to environmental concerns, the humane treatment of animals is viewed as important for both altruistic and food safety reasons [13]. Organic users believe that animals are better treated in organic farms, and that will lead to a better-quality product. The increasing demand for free-range eggs supports this association [13].

Overall, consumers are especially concerned about the potential harm that conventional food will bring to their personal health and public health, for example the development of allergies in youth [18]. Life events, such as new life born, are also motivators to shift from conventional food to organic food [1]. Indeed, families with children are more likely to buy organic [19]. Parents concerned about perceived effects of growth hormones and antibiotics start purchasing organic foods during pregnancy or when their baby transitions to baby food [20]. Due to these connections, this investigation will take 'household' as a main factor to test whether young children contribute to preference for organic or local foods.

Income is a consumer demographic factor that significantly influences consumers' decisions. According to Zepeda and Deal's research [1], both organic and conventional shoppers cited prices as an impediment to buying organic foods. High-income people found price as much of a barrier as low-income people. Thus, price differential (context) represents more of an attitudinal barrier than a financial barrier. It is more about how consumers choose to spend their money. In this investigation, income was included as a part of the demographic questions. Compared to conventional shoppers, organic users, especially heavy users, tend to shop at more venues such as farmers' markets, or directly from farms. This behavior reflects that heavy users are more likely to value knowing where their food came from and want to have a relationship with farmers. While this correlation suggests an overlap between organic and local, the production methods do not necessarily coincide.

\section{Rise and preference for locally grown and produced food}

While "local" has received much attention and promotion in recent years in the U.S., as previously mentioned, the term has not been officially defined. According to Zepeda [16] the lack of a consistent and clear definition is a primary stumbling block in analyzing local-food demand. According to previous research, the most popular ways to define local food are by political boundaries and by store type [16]. Consumers tend to define local food as food produced in the same state and the neighboring counties of their residence. Two other popular definitions of "local" are food purchased from farmers' markets or food grown/produced by smaller, independent farms and manufacturers [6]. Although there is no authoritative definition for locally grown/processed food, this inconsistency does not appear to impact consumer preference for locally grown food [21]. For this investigation, local will use a prevalent definition and will refer to food grown/produced within 100 miles from consumers' residence.

The contribution of local food sales to the overall food economy varies substantially by region, and depends on different states' production mix, population density and geographic proximity to farms. Vegetable, fruit, and nut farms dominate local food sales. Local direct-to-consumer sales excel where climate and topography favor fruit and vegetable production; where there is proximity to farmer markets and neighboring local food farms; and where there is access to transportation information networks [22]. The 
value of local food sold in the US is highest in metropolitan areas and is geographically concentrated in the Northeast and on the West coast [23]. Consumers cite multiple reasons for purchasing locally grown/produced food. According to AT Kearney [24], the top reasons consumers purchase locally grown/produced food are because they believe buying local assists the local economies (66\%), delivers a broader and better assortment of products (60\%), provides healthier alternatives (45\%), improves the carbon footprint (19\%), and helps increase natural or organic production (19\%). Zepeda [9] obtained similar findings from focus groups: consumers associate local with supporting local economy and the environment. Moreover, they found that participants only had positive attitudes towards local foods.

Major obstacles for many consumers in purchasing local food are search costs and accessibility [25]. The venue where consumers do their primary food shopping has an impact on consumers' local food preference. Shopping at a health food store increases the probability of buying local food by $19 \%$ [16]. Trust in different venues can impact consumers' food purchasing decisions. A.T. Kearney [24] had consumers rate how much they trust different venues on delivering local food (on a scale from 1-10, with 10 being the most trusted). Consumers rated farmers markets most trustworthy (8.2), followed by natural food markets (7.8), locally owned supermarkets (7.4), national supermarkets (6.6), big box retailers (5.4), and lastly online grocers (5.0). According to these results, it seemed that although local food is available in multiple venues, lack of credence in some of the venues may be an obstacle preventing consumers from purchasing more local food.

\section{Methodology}

The research was conducted on three different foods: tomatoes, apples, and dairy. Only products that had a possibility to be sold as both local and organic were considered. It would not have been effective, for example, to include mangoes which cannot be found as local in the USA. The three selected foods were chosen since they have significant frequency of purchase, and both apples and dairy have been previously studied [26,27]. Additionally, these three categories are the most popular local food categories [6] most frequently purchased by consumers, but also available as organic.

\section{Research hypotheses}

To accomplish the research objectives, the current study examined two hypotheses repeated for each of the three food groups:

a) H01: When consumers make purchase decisions to buy either organic or locally grown food, they value organic and locally grown equally.

b) H02: When both organic food and locally grown food are available in the market, the price will be equal in importance to other product attributes in determining consumers' purchase decisions.

\section{Research design}

The research objective was accomplished through six-step consumer market research supported by secondary information available from industry reports and academic research studies. This integrated research process consisted of the following:

a) Design of conjoint analysis

b) Questionnaire development

c) Pretest of the online survey

d) Revision of the questionnaire

e) Fielding of the online survey

f) Data analysis

In order to be qualified to take this survey, respondents had to be: 1) US. Residents; 2) over 18 years old; 3) be responsible for most of (at least 50\%) the food shopping for his/her household; and 4) had purchased tomatoes, apples, and dairy milk in the previous 3 months. The questionnaire was launched through MTurk, an online web-based platform for recruiting and paying subjects to perform research. The sample was a convenience sample. Convenience sampling is one of the most common sampling methods in academic as well as practicing marketing research.

\section{Conjoint analysis}

The research analysis primarily employed choice based conjoint analysis, a multivariate technique developed specifically to understand how respondents develop preferences for any type of product or service. Conjoint analysis is a decomposition method that estimates the structure of buyers' preferences for a product's attributes, given the buyers' overall evaluations of a set of alternative products that are pre-specified in terms of levels of different attributes [28]. In conjoint analysis, a product is viewed as a combination of attributes and attribute levels. These attributes reflect important product characteristics hypothesized to have high impact on a buyer's product purchase behavior. Attribute levels correspond to different points along these characteristics and should span the realistic range of each attribute. Conjoint analysis is based on the simple premise that consumers evaluate the value of a product (real or hypothetical) by combining the separate amount of value provided by each attribute. Consumers can best provide their estimates of preferences by judging products formed by combinations of attributes. A major advantage of conjoint analysis is the high degree of realism in portraying consumer choices. This method is much more representative of the actual process of selecting a product from a set of competing products [29]. 
The design of a conjoint analysis experiment includes two basic steps. First, the attributes and attribute levels that define the conjoint design must be carefully selected. Together, the number of attributes and their associated levels compose the design specifications for the conjoint analysis experiment. For each of the three food product categories, there were between five and seven product attributes with between two and six levels. The actual attributes used in the conjoint analyses were based on previous research. The selection of the five tomato attributes (production method, price, variety, color, and seasonality) and attribute levels, shown in Table 1, involved both focus groups and previous research [30]. The seven attributes for the apple conjoint analysis (production method, price, variety, flavor, size, texture, and blemish), shown in Table 2, were taken from previous research on local and organic apples [26].

Table 1: Tomato Conjoint Preference Model Estimation Results, Range and Calculated Attribute Importance (\%) for Five Tomato

\begin{tabular}{|c|c|c|c|c|c|c|c|}
\hline \multirow[t]{2}{*}{ Attribute } & \multirow[t]{2}{*}{ Attribute Level } & \multirow{2}{*}{$\begin{array}{c}\begin{array}{c}\text { Unstandardized } \\
\text { Coefficients }\end{array} \\
\text { B } \\
\end{array}$} & \multirow[b]{2}{*}{ Std. Error } & \multirow[t]{2}{*}{$\mathbf{T}$} & \multirow[t]{2}{*}{ Sig. } & \multirow[t]{2}{*}{ Range } & \multirow{2}{*}{$\begin{array}{l}\text { Attribute } \\
\text { Importance }\end{array}$} \\
\hline & & & & & & & \\
\hline Production & No mention & 0.69 & & & & 1.27 & $19.40 \%$ \\
\hline \multirow[t]{3}{*}{ Method } & Organic & -0.99 & 0.5 & -1.99 & 0.05 & & \\
\hline & Locally Grown & 0.78 & 0.38 & 2.06 & 0.05 & & \\
\hline & All Natural & -0.49 & 0.4 & -1.24 & 0.22 & & \\
\hline \multirow[t]{3}{*}{ Price/lb* } & $\$ 1.26$ & -0.24 & & & & 0.9 & $13.70 \%$ \\
\hline & $\$ 2.67$ & 0.57 & 0.31 & 0.18 & 0.86 & & \\
\hline & $\$ 3.99$ & -0.33 & 0.31 & -1.06 & 0.3 & & \\
\hline \multirow[t]{4}{*}{ Variety } & Beefsteak & 0.72 & & & & 1.55 & $23.70 \%$ \\
\hline & Cherry & -0.83 & 0.4 & -2.08 & 0.04 & & \\
\hline & Heirloom & 0.47 & 0.36 & 1.31 & 0.2 & & \\
\hline & Roma & 0.58 & 0.36 & 1.62 & 0.11 & & \\
\hline \multirow[t]{4}{*}{ Color } & Green & -0.3 & & & & 1.3 & $19.90 \%$ \\
\hline & Red & 0.91 & 0.36 & 2.57 & 0.01 & & \\
\hline & $\begin{array}{l}\text { Green w/some } \\
\text { red }\end{array}$ & -0.39 & 0.38 & -1.02 & 0.32 & & \\
\hline & $\begin{array}{l}\text { Red w/some } \\
\text { green }\end{array}$ & -0.22 & 0.41 & 0.55 & 0.59 & & \\
\hline \multirow[t]{2}{*}{ Seasonality } & In Season & 0.76 & & & & 1.52 & $23.30 \%$ \\
\hline & Out of Season & -0.76 & 0.23 & -3.25 & 0 & & \\
\hline Total: & & & & & & 6.54 & $100 \%$ \\
\hline
\end{tabular}

Note that economic theory would suggest that price should be most important when making a choice when all else is equal. Clearly the objective of the conjoint is to have choices where "all else is not equal." In this analysis consumers showed that given the other attributes major did not have a significant influence on their choice.

Table 2: Apple Conjoint Preference Model Estimation Results, Range and Calculated Attribute Importance (\%) for Seven Apple Attributes.

\begin{tabular}{|c|c|c|c|c|c|c|c|}
\hline \multirow[t]{2}{*}{ Attribute } & \multirow[t]{2}{*}{ Attribute Level } & \multirow{2}{*}{$\begin{array}{c}\begin{array}{c}\text { Unstandardized } \\
\text { Coefficients }\end{array} \\
\text { B } \\
\end{array}$} & \multirow[b]{2}{*}{ Std. Error } & \multirow[t]{2}{*}{$\mathbf{T}$} & \multirow[t]{2}{*}{ Sig. } & \multirow[t]{2}{*}{ Range } & \multirow[t]{2}{*}{$\begin{array}{l}\text { Attribute } \\
\text { Importance }\end{array}$} \\
\hline & & & & & & & \\
\hline Production & No Mention & -0.12 & & & & 0.37 & $11.40 \%$ \\
\hline \multirow[t]{3}{*}{ Method } & Organic & -0.1 & 0.24 & -0.41 & 0.68 & & \\
\hline & Locally Grown & 0.24 & 0.23 & 1.05 & 0.3 & & \\
\hline & All Natural & -0.02 & 0.22 & -0.09 & 0.92 & & \\
\hline \multirow[t]{3}{*}{ Price } & $\$ 0.99 /$ pound & -0.01 & & & & 0.48 & $14.90 \%$ \\
\hline & $\$ 1.29 /$ pound & 0.25 & 0.21 & 1.18 & 0.24 & & \\
\hline & $\$ 2.99 /$ pound & -0.23 & 0.22 & -1.07 & 0.29 & & \\
\hline \multirow[t]{3}{*}{ Variety } & Gala & -0.19 & & & & 0.47 & $14.50 \%$ \\
\hline & McIntosh & 0.28 & 1.2 & 0.24 & & & \\
\hline & Fuji & 0.1 & 0.1 & 0.45 & 0.66 & & \\
\hline
\end{tabular}




\begin{tabular}{|c|c|c|c|c|c|c|c|}
\hline & Red Delicious & -0.19 & 0.23 & -0.82 & 0.42 & & \\
\hline \multirow[t]{2}{*}{ Flavor } & Sweet & 0.17 & & & & 0.33 & $10.30 \%$ \\
\hline & Tart & -0.17 & 0.13 & -1.25 & 0.21 & & \\
\hline \multirow[t]{3}{*}{ Size } & Small & 0.12 & & & & 0.84 & $26.00 \%$ \\
\hline & Medium & 0.36 & 0.2 & 1.76 & 0.08 & & \\
\hline & Large & 0.48 & 0.21 & -2.28 & 0.03 & & \\
\hline \multirow[t]{2}{*}{ Texture } & Crisp & -0.03 & & & & 0.06 & $2.00 \%$ \\
\hline & Mealy & 0.03 & 0.03 & 0.23 & 0.82 & & \\
\hline \multirow[t]{3}{*}{ Blemish } & Blemish Free & 0.3 & & & & 0.67 & $20.90 \%$ \\
\hline & $\begin{array}{l}\text { Very Few } \\
\text { Blemish }\end{array}$ & 0.07 & 0.19 & 0.38 & 0.71 & & \\
\hline & Some Blemish & -0.37 & 0.2 & -1.83 & 0.07 & & \\
\hline Total: & & & & & & 3.22 & $100 \%$ \\
\hline
\end{tabular}

Table 3: Dairy Milk Conjoint Preference Model Estimation Results, Range and Calculated Attribute Importance (\%) for Five Milk Attributes.

\begin{tabular}{|c|c|c|c|c|c|c|c|}
\hline \multirow[t]{2}{*}{ Attribute } & \multirow[t]{2}{*}{ Attribute Level } & \multirow{2}{*}{$\begin{array}{c}\begin{array}{c}\text { Unstandardized } \\
\text { Coefficients }\end{array} \\
\text { B }\end{array}$} & \multirow[b]{2}{*}{ Std. Error } & \multirow[t]{2}{*}{$\mathbf{T}$} & \multirow[t]{2}{*}{ Sig. } & \multirow[t]{2}{*}{ Range } & \multirow[t]{2}{*}{$\begin{array}{l}\text { Attribute } \\
\text { Importance }\end{array}$} \\
\hline & & & & & & & \\
\hline \multirow[t]{4}{*}{$\begin{array}{l}\text { Production } \\
\text { Method }\end{array}$} & No Mention & -0.12 & & & & 0.64 & $17.40 \%$ \\
\hline & Organic & 0.16 & 0.19 & 0.84 & 0.4 & & \\
\hline & Locally Produced & 0.3 & 0.2 & 2.06 & 0.05 & & \\
\hline & All Natural & -0.34 & 0.18 & -1.24 & 0.22 & & \\
\hline \multirow[t]{3}{*}{ Price/gal } & $\$ 3.21 /$ gallon & 0.55 & & & & 1.02 & $27.60 \%$ \\
\hline & $\$ 3.80 /$ gallon & -0.07 & 0.16 & -0.45 & 0.66 & & \\
\hline & $\$ 4.18 /$ gallon & -0.47 & 0.16 & -2.91 & 0 & & \\
\hline \multirow[t]{3}{*}{$\begin{array}{l}\text { Structure/ } \\
\text { Function }\end{array}$} & No Mention & 0.29 & & & & 0.39 & $10.60 \%$ \\
\hline & $\begin{array}{l}\text { Protein and potassium in } \\
\text { milk helps maintain strong } \\
\text { muscles }\end{array}$ & 0.19 & 0.17 & 1.12 & 0.27 & & \\
\hline & $\begin{array}{l}\text { Calcium and Vitamin D in milk } \\
\text { helps build strong bones }\end{array}$ & -0.1 & 0.17 & -0.61 & 0.54 & & \\
\hline \multirow[t]{3}{*}{$\begin{array}{l}\text { Nutrient } \\
\text { Content }\end{array}$} & No Mention & -0.09 & & & & 0.27 & $7.30 \%$ \\
\hline & Good Source of Protein & -0.09 & 0.18 & -0.5 & 0.62 & & \\
\hline & $\begin{array}{c}\text { Excellent Source of Calcium } \\
\text { and Vitamin D }\end{array}$ & 0.18 & 0.18 & 1 & 0.32 & & \\
\hline \multirow[t]{6}{*}{ Negative Labels } & No Mention & -0.59 & & & & 1.37 & $37.10 \%$ \\
\hline & $\begin{array}{l}\text { Our farmers pledge not to use } \\
\text { artificial growth hormone }\end{array}$ & 0.59 & 0.21 & 2.88 & 0 & & \\
\hline & $\begin{array}{c}\text { From cows not treated with } \\
\text { antibiotics }\end{array}$ & 0.3 & 0.26 & 1.12 & 0.27 & & \\
\hline & No artificial ingredients & 0.6 & 0.26 & 2.26 & 0.03 & & \\
\hline & No acrylamide & -0.2 & 0.32 & -0.64 & 0.52 & & \\
\hline & No strophe amine & -0.77 & 0.3 & 2.57 & 0.01 & & \\
\hline Total: & & & & & & 3.7 & $100 \%$ \\
\hline
\end{tabular}


In the case of dairy milk, the five attributes (production method, price, structure/function, nutrient content and negative labels) listed in Table 3 were based on an extensive study including secondary research, focus groups and conjoint analysis [31]. The dairy milk conjoint analysis was the only analysis that included an attribute titled "negative claim." A negative claim specifies what is NOT in the product as opposed to most attributes which describe what is in the product. For example, "no artificial ingredients" is a negative claim and "rich in calcium" is a positive claim. Two of the six negative labels were fake labels: one was "No acrylamide", and the other was "No strophe amine." The objective for making up these two fake labels was to test consumers' attitudes toward negative labels. The assumption was that although consumers might have no knowledge of the fake negative labels, the presence of the fake labels with the word "no" might decrease consumers' preference for the product.

Once the product attributes and attribute levels have been selected, they must be combined into complete products, with each product consisting of one level of each of the product's attributes.
In a full-factorial design, every possible combination of attribute level is evaluated. For this study, the possible number of attribute level combinations would result in 384 different tomato products, 1,728 apple products, and 648 dairy milk products. A fractionalfactorial design was used instead, in which an orthogonal subset of attribute level combinations was obtained from the SPSS data function. Given the large number of attributes and attribute levels for all three conjoint analyses, the orthogonal conjoint models still required a large number of hypothetical products. When the number of products to be judged becomes very large, the task becomes unrealistic for a survey participant. A Balanced Incomplete Block Design (BIBD) was utilized; the tomato, apple and dairy products were separated into choice sets known as blocks. Each block consisted of four choices of products, including three products and one "would not choose any of these" alternative. There were 16 blocks for tomatoes, 32 blocks for apples, and 31 blocks for dairy milk. Product pictures were provided for the five varieties of tomatoes and the four varieties of apples [32]. A sample of a conjoint choice block is shown in Figure 1.

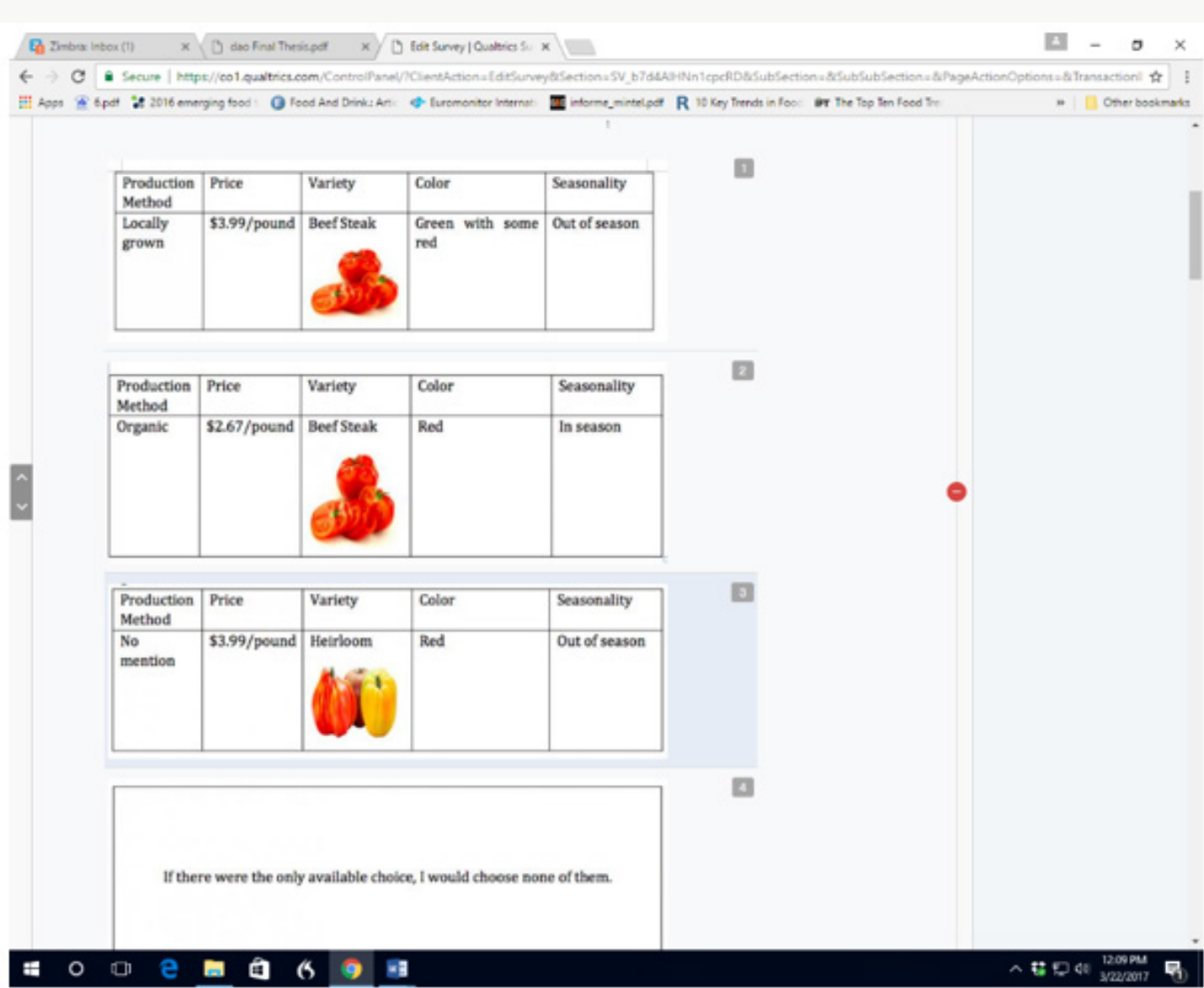

Figure 1: Example of a Conjoint Decision Choice Block for Tomatoes.

\section{Questionnaire development}

To collect consumers' food shopping preference opinions, an online survey was conducted. The questionnaire was designed on
Qualtrics.com, a reliable survey hosting website, and was divided into four parts:

a) Screening questions 
b) Food shopping behavior and preferences

c) Three conjoint analysis questions

d) Demographic questions

To be qualified for the survey, respondents had to be U.S. residents over 18 years old that were responsible for most of (at least 50\%) the food shopping for his/her household. Additionally, participants had to have purchased tomatoes, apples, and dairy milk in the previous three months.

Respondents were also asked a series of questions about their shopping preferences, such as where they did the most of their food shopping and how frequently they purchased organic and local food. The demographic section asked respondents general demographic questions such as age, gender, and income.

The conjoint analysis portion of the questionnaire included the tomato conjoint, the apple conjoint, and the dairy milk conjoint. Survey respondents were shown only one block for each of the three food categories, and all blocks appeared randomly. Respondents were asked to select one preferred product choice for each block. The dependent variable was "likelihood to buy" and the independent variables varied by product category and can be found in Table 1 through 3. For the tomato conjoint question, the survey instructions were: Below are three tomato profiles described in terms of Production Method, Price, Variety, Color, and Seasonality. Please choose one that you are most likely to buy. If you would not purchase tomatoes (or would delay your purchase) assuming these were the only options available, check the box "If these were the only options available, I would choose none of them."

\section{Pretest of online survey}

Before the formal launch, pre-tests were conducted to calculate the average finish time and test the performance of this survey. To get feedback directly from respondents, the first survey used a small convenience sample. There were 58 people who started the survey; 47 of them were qualified and completed the survey. When the qualified respondents were asked their feelings about the survey, the most frequently mentioned feedback was that the time spent on the survey was too long. The average time to finish the survey was 15 minutes. After survey modifications were made, a final pre-test was launched on Amazon Mechanic Turk (MTurk). Fifteen qualified respondents took the modified survey. The average time to complete the survey was 9 minutes 41 seconds, which was within 10 minutes. There were no obvious problems in the results, so after the final pre-test, the survey was formally launched on Mturk.

\section{Participants}

The questionnaire was launched through MTurk, an online web-based platform for recruiting and paying subjects to perform research. The sample was a convenience sample. Convenience sampling is one of the most common sampling methods in academic as well as practicing marketing research [33]. Among all respondents who started the survey, 400 of them were qualified and completed the survey.

\section{Data Analysis}

Choice based conjoint analysis was used in this study to examine consumer valuation of major attributes of choosing organic food or locally grown food. Conjoint has previously been used by Yue [34] to investigate Organic and local for fresh produce. In conjoint analysis, a buyer's utility for a product, represented by the preferred product selections, is the sum of the buyer's utilities for each product attribute. In the econometric specification of consumer preferences, the product attributes are combined to formulate an additive conjoint preference model. The measurement scale properties of the dependent variable (product preference) determine the choice of model estimation method. The actual method of data collection was for the respondent to simply check in the box next to each choice the one which they would be most likely to buy among the 4 choices. The check box can be seen in Figure 1. Ordinary least squares (OLS) was used to estimate the conjoint preference model attribute parameters because it has an important advantage over other methods of providing standard errors for the estimated parameters [28]. The SPSS data analysis software used to perform the data analysis for all three conjoint analyses.

The fundamental application of the conjoint preference model is the calculation of attribute utility values and attributes' relative importance from the estimated parameters. The estimated mean attribute rating for each attribute level provides a direct measure of utility. Since all attribute utility results are expressed in a common unit, utility ranges can be compared from attribute to attribute. The relative importance of a product attribute is estimated as the range of estimated parameters over all levels of that attribute, expressed as a percentage of the sum of the parameter ranges for all attributes [26].

\section{Results and Discussion}

This study examined two hypotheses concerning consumers' preferences for organic versus locally grown food products. H01 proposed that when organic food and locally grown foods are available in the market at the same time consumers would value organic and locally grown equally. $\mathrm{H} 02$ posited that price would be equal in importance to other product attributes in determining consumers' purchase decisions. These hypotheses were tested by a series of three choice based conjoint analyses, one each for tomatoes, apples and dairy milk. The OLS parameter estimates and calculated attribute relative importance value results are shown in Tables 1-3.

\section{Tomato conjoint analysis}

There were five attributes in the tomato conjoint analysis: production method, price, variety, color, and seasonality, with two 
to four levels for each attribute. The OLS results and calculated attribute relative importance values shown in Table 1 indicated that when consumers decided to purchase tomatoes, among the five attributes, "variety" had the most important impact on their purchase decisions, with a factor importance of $23.7 \%$. Among the four varieties of tomatoes, respondents claimed to value beefsteak tomatoes more than the other three varieties. This suggests that when a consumer goes to a venue to purchase some tomatoes, it's more likely for the consumer to pick a beefsteak tomato if the variety is available.

The second most important factor for consumers' tomato shopping was seasonality; the factor importance was $23.30 \%$. Respondents claimed that between the two seasonality levels (inseason and out-of-season), they valued in-season more. The third most important tomato attribute was color; the factor importance was $19.87 \%$. Among the four levels of color, respondents claimed that they valued red the most. The fourth important attribute was production method; the factor importance was $19.9 \%$. Among the four levels of production method, respondents claimed to value locally grown the most, which indicated that when consumers have options to choose between organic and locally grown the same time, consumers prefer locally grown tomatoes to organic tomatoes. The first hypothesis was rejected. Unexpectedly, for consumers, price was the least important tomato attribute; the factor importance was only $13.7 \%$. The second hypothesis that price would be equally important to other product attributes was rejected. The relative unimportance of price, compared to other tomato attributes, is consistent with previous research by Manalo [35] suggesting that consumers do not give much importance to price, at least when price is within the range of prices normally found in stores.

Of the three tomato price levels, the middle price of $\$ 2.67$ conferred the highest utility of the three price levels. This result is counter to traditional economic theory which suggests a negative correlation between price and utility, with utility decreasing as price increases. One possible explanation relates to consumers' reference prices and perceptions of price versus quality. The $\$ 2.67$ price may have been closest to consumers' normal reference price for high quality tomatoes, with the lower $\$ 1.26$ price being equated to lower quality tomatoes and the highest $\$ 3.99$ price being viewed as too high for tomatoes. The First-Choice product is determined by combining the attribute levels with the highest consumer utility. For tomatoes, the First-Choice product was a red, in season, locally grown beefsteak tomato, sold at a price of $\$ 2.67$ per pound.

\section{Apple conjoint analysis}

Table 2 shows OLS results of the apple conjoint analysis and the calculated attribute relative importance values. There were seven attributes in the apple conjoint analysis: production method, price, variety, flavor, size, texture, and blemish. For each of the attributes, two to four levels were used. When consumers considered purchasing some apples, they valued size the most; the attribute importance was $26.0 \%$. Among the three size levels, respondents claimed to value the large size the most, which means when consumers purchase apples, there is greater likelihood for consumers to choose a large size apple. The second most important attribute was blemish; the factor importance was $20.9 \%$, with blemish free apples being preferred. Price was the third most important apple attribute, with relative importance of $14.9 \%$, so the second null hypotheses that price would be equal in importance to other product attributes cannot be rejected. This result is different from tomatoes, where price was the least important attribute. Among the three price levels, the middle price of $\$ 1.29$ per pound conferred the highest utility. This price result is similar to the tomato conjoint analysis price results, probably for the same reasons. The fourth most important attribute was apple variety; the factor importance was $14.5 \%$, very close to the importance of price. Among the four apple varieties included in the conjoint analysis, McIntosh was the preferred variety for responding consumers.

The fifth apple attribute in importance was production method, with attribute importance of $11.4 \%$. Among the four production method levels, locally grown produced the highest consumer utility, which indicated that when consumers have the option to choose organic and locally at the same time, they prefer locally grown food to organic food. This result is consistent with the tomato conjoint analysis results and leads to rejecting the first null hypothesis that consumers would value organic and locally grown equally.

The sixth most important attribute was flavor, with a $10.3 \%$ relative importance. The least important apple attribute for responding consumers was texture, with only $2.0 \%$ relative importance and not statistically significant. The apple results indicated that consumers prefer a mealy apple more than a crisp apple, which is counterintuitive and directly contradicts results from previous apple conjoint analyses, in which crisp texture was preferred to mealy texture $[26,35]$. The differing results between this study and previous apple conjoint analyses may be attributable to major differences in the conjoint designs, especially the selection of apple attributes and attribute levels.

A comparison of the tomato and apple conjoint analysis results provides additional insight into consumers' selection process and the importance played by different types of attributes. In the tomato conjoint analysis, the two most important attributes were variety and seasonality, while in the apple conjoint analysis, the two most important attributes were size and blemish [36]. Three of these four attributes are extrinsic search attributes that serve to differentiate products. When consumers consider purchasing both tomatoes and apples, they tend to rely on search characteristics to help them select products. 


\section{Dairy milk conjoint analysis}

There were five attributes in the dairy milk conjoint analysis: production method, price, structure/function, nutrient content and negative labels. Each of the attributes had two to six levels. Table 3 shows OLS estimates along with the calculated attribute relative importance values. When consumers decided to purchase dairy milk, the most important attribute was negative labels, a credence attribute; the attribute importance was $37.1 \%$. The two fake negative labels did have significant impact on consumers' decisions. Consumers had the least likelihood to purchase dairy milk with "No strophe amine" label on the package. The "Our farmers pledge not use artificial growth hormone" label would help increase consumers likelihood to purchase [37].

The second most important attribute was Price; the attribute importance was $27.6 \%$. Of the three price levels, respondents tended to choose the lowest price, which was $\$ 3.21$ per gallon. The price results, both the high relative importance of price and the negative correlation between price and utility, were consistent with economic theory for undifferentiated products, like dairy milk The third most important attribute was production method, with $17.4 \%$ attribute importance. Among the three production method levels, consumers preferred locally produced dairy milk to the other three types of dairy milk and locally produced milk had a significant positive impact on consumers' decision. Thus, the null of the first research hypothesis is rejected. Consumers' preferences for local produced dairy milk are consistent with tomato and apple preferences. The fourth attribute in importance was structure/ function; the factor importance was $10.6 \%$. Among the three levels, respondents claimed that they valued "the strong muscle" function the most. The least important dairy milk attribute was nutrient content; the factor importance was $7.3 \%$.

The most popular combination of dairy milk was locally produced milk with excellent source of calcium and Vitamin D, has no artificial ingredients inside, and sold at \$3.21/gallon. The combination result was shown in Table 3. A comparison of the dairy milk conjoint results with the tomato and apple conjoint results shows some similarities. Although production method was not the most important attribute that consumers valued, of the four different production method levels, consumers preferred locally grown/produced for all three products. However, unlike tomatoes and apples, when consumers consider purchasing dairy milk, price has great impact on consumers' decisions [38]. Dairy milk is a commodity, with very few search attributes to differentiate dairy milk products in the stores. In the absence of product differentiation from search attributes, price becomes much more important in the consumer decision making process.

For all three products, the null hypothesis of hypothesis 1 was rejected, which suggests that when there are multiple production method choices in the market simultaneously, consumers do have a preference. Consumers prefer locally grown to organic or the other production methods. Hypothesis 2 proposed that price is the main factor in determining consumers' purchase decisions. It is widely accepted, among both academics and practicing food marketers, that for most unbranded consumer commodity products, price dominates other attributes. One purpose of this research was to test whether or not these unbranded consumer commodity products actually have attributes that are either intrinsic or extrinsic which appear to have a greater importance in affecting among consumers' preferences. According to the conjoint results, price was not the most important attribute for any of the three products. The attribute importance ranking of price was the fifth of five tomato attributes, third of seven apple attributes for apples and second of five dairy milk attributes. The null hypothesis of hypothesis 2 was rejected. Price was not the most important attribute influencing consumers' food purchase decisions. The importance of price varies from food category to food category.

\section{Conclusion}

In response to the growing need for information about consumers' opinions toward locally grown/processed food and organic food, this study has examined consumers' preferences between organic food and locally grown food with different product attributes through three conjoint analyses. A convenience sample of 400 respondents was used to conduct the study. The results of the three conjoint analyses suggested four conclusions. First, when virtually the same organic food and locally grown food were available in the market at the same time, consumers preferred to choose locally grown food. However, when consumers made food purchase decisions, the production method was not the most important attribute for them. The most important attribute varied from food product to product. For tomatoes, when consumers made purchase decisions, the most important attribute they valued was variety. For apples, the most important attribute consumers valued was size. For dairy milk, the most important attribute they valued was negative labels. However, the result of the impact of negative labels on consumers' purchase decisions was opposite the initial assumption.

The assumption was that the negative dairy milk labels would reduce consumers' likelihood to buy when they saw the negative label. But the result indicated that not all negative labels reduce consumers' likelihood to buy. When consumers saw labels such as "our farmers pledge not use artificial growth hormone" the positive aspects increased the likelihood of purchase. One possible explanation was that in the absence of extrinsic search attributes in dairy milk, credence attributes such as label claims become more important in consumer decision making. The conclusions offered good marketing intelligence about consumers' needs and preferences to food producers and suppliers. Consumers clearly prefer locally grown food to foods grown with other production 
methods, including organic food. To better serve the customers and meet their demands, producers and suppliers may yield higher margins by focusing more on the local food industry.

\section{References}

1. Zepeda L, D Deal (2009) Organic and Local Food Consumer Behavior: Alphabet Theory. International Journal of Consumer Studies 33(6): 697705.

2. Sifferlin A (2015) There's a Record Number of Organic Farms and Processing Facilities in the U.S. Time Magazine, April 15.

3. Specialty Food News (2016) Organic Sales Grow in 2016.

4. US Department of Agriculture, Economic Research Service (2013) Fruit and Vegetable Prices.

5. US Department of Agriculture, Agricultural Marketing Service (2012) Organic Labeling.

6. Lang M, J Stanton, Yingdao Qu (2014) Consumers' Evolving Definition and Expectations for Local Foods. British Food Journal 116(11): 18081820.

7. Slattery E, M Livingston, C Greene, K Klonsky (2011) Characteristics of Conventional and Organic Apple Production in the United States. Department of Agriculture, Economic Research Service, Washington, USA.

8. Peterson HH, LD Burbidge (2012) Japanese Consumers' Valuation of U.S. Beef and Pork Products after the Beef Trade Ban. Journal of Agricultural and Resource Economics 37(1): 58-76.

9. Zepeda L, C Leviten Reid (2004) Consumers' Views on Local Food. Journal of Food Distribution Research 35(3): 1-6.

10. Daniells S (2014) U.S. Organic Food Market to Grow 14\% from 2013-18.

11. Botonaki A, K Polymeros, E Tsakiridou, K Mattas (2006) The Role of Food Quality Certification on Consumers' Food Choices. British Food Journal 108(2): 77-90.

12. Chryssohoidis GM, A Krystallis (2005) Organic Consumers' Personal Values Research: Testing and Validating the List of Values (LOV) Scale and Implementing a Value-Based Segmentation Task. Food Quality and Preference 16(7): 585-599.

13. Harper GCA, Makatouni A (2002) Consumer Perception of Organic Food Production and Farm Animal Welfare. British Food Journal 104: 287 299.

14. Magnusson MK, A Arvola, UK Hursti, L Aberg, PO Sjoden (2001) Attitudes towards Organic Foods among Swedish Consumers. British Food Journal 103(3): 209-27.

15. Makatouni A (2002) What Motivates Consumers to Buy Organic Food in the UK: Results from a Qualitative Study. British Food Journal 104(3): $345-52$.

16. Zepeda L, J Li (2006) Who Buys Local Food? Journal of Food Distribution Research 37(3): 1-11.

17. Harris B, D Burress, S Eicher (2000) Demands for Local and Organic Produce: A Brief Review of the Literature. Institute for Public Policy and Business Research, University of Kansas, Lawrence, USA.

18. Midmore P, S Naspetti, A Sherwood, D Vairo, M Wier, et al. (2005) Consumer Attitudes towards the Quality and Safety of Organic and Low input Foods: A Review. Quality Low Input Food Report, QLIF-Project.
19. Thompson GD, J Kidwell (1998) Explaining the Choice of Organic Produce: Cosmetic Defects, Prices, and Consumer Preferences. American Journal of Agricultural Economics 80(2): 277-287.

20. The Food Institute (2015) Food Industry Review, 2014 Edition. Upper Saddle River, New Jersey, USA.

21. Thilmany D, CA Bond, JK Bond (2008) Going Local: Exploring Consumer Behavior and Motivations for Direct Food Purchases. American Journal of Agricultural Economics 90(5): 1303-1309.

22. Low SA, S Vogel (2011) Direct and Intermediated Marketing of Local Foods in the United States. U.S. Department of Agriculture, Economic Research Service, ERS Report 128, Washington, USA.

23. Carroll KA, JC Bernard, JD Pesek (2013) Consumer Preferences for Tomatoes: The Influence of Local, Organic, and State Program Promotions by Purchasing Venue. Journal of Agricultural and Resource Economics 38(3): 379-396.

24. Kearney AT (2013) Buying into the Local Food Movement.

25. Eastwood D, J Brooker, M Gary (1999) Location and Other Market Attributes Affecting Farmers Market Patronage: The Case of Tennessee. Journal of Food Distribution Research 30(1): 63-72.

26. Wirth FF, JL Stanton, JB Wiley (2011) The Relative Importance of Search versus Credence Product Attributes: Organic and Locally Grown. Agricultural and Resource Economics Review 40(1): 48-62.

27. Stanton JL, J Wiley (2013) The Influence of Label Messages on Fluid Milk: A Conjoint Analysis. Conference Proceedings. International Food Marketing Research Symposium 2013. Institute of Food Products Marketing. ISBN 978-0-9856080-1-9 June 20-21, 2013.

28. Green PE, V Srinivasan (1978) Conjoint Analysis in Consumer Research: Issues and Outlook. Journal of Consumer Research 5(2): 103-123.

29. Hair JF, WC Black, BJ Babin, RE Anderson (2009) Multivariate Data Analysis, ( $7^{\text {th }}$ edn.). Upper Saddle River, Pearson Prentice Hall, New Jersey, USA.

30. Cantwell M (2012) Mature Fruit Vegetables; Tomato Quality Attributes. Postharvest Technology Short Course, University of California, California, USA.

31. Salnikova K (2014) An Analysis of Front-of-Package Claims for Fluid Milk Labels: Discrete Choice Experiment. MS thesis, Department of Food Marketing, Saint Joseph's University, USA.

32. Sung E (2013) A Visual Guide to Apples.

33. Doyle C (2011) A Dictionary of Marketing. Oxford University Press Inc, New York, USA.

34.Yue C, C Tong (2009) Organic or Local? Investigating Consumer Preference for Fresh Produce Using a Choice Experiment with Real Economic Incentives, Hort Science 44: 366-371.

35. Manalo AB (1990) Assessing the Importance of Apple Attributes: An Agricultural Application of Conjoint Analysis. Northeastern Journal of Agricultural and Resource Economics 19(2): 118-124.

36. Gastelum Barrios A, R Borquez Lopez, E Rico Garcia, M Toledano Ayala, G Soto Zarazua (2011) Tomato Quality Evaluation with Image Processing: A Review. African Journal of Agricultural Research 6(14): 3333-3339.

37. US Department of Agriculture, Agricultural Marketing Service (2013) Local Food Research and Development.

38. US Department of Agriculture, National Agricultural Library (2016) Organic Production/Organic Food: Information Access Tools. 
(C) This work is licensed under Creative

To Submit Your Article Click Here: Submit Article

DOI: $10.32474 /$ CIACR.2018.04.000180

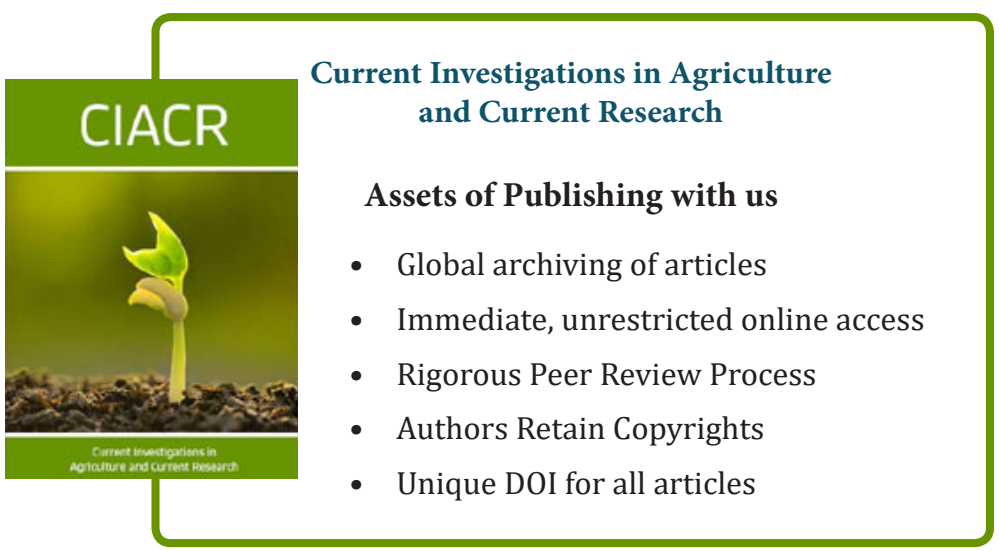

